\title{
Faktor yang Berhubungan dengan Kejadian Low Back Pain pada Pekerja Pembuat Batu Bata (cross sectional study)
}

\author{
Anggi Isnani Parinduri ${ }^{1, *}$, Fadlilah Widyaningsih ${ }^{2}$, Irmayani $^{3}$, Rosita Ginting ${ }^{4}$, Raisha Octavariny ${ }^{5}$ \\ I,2,3,4,5 Institut Kesehatan Medistra Lubuk Pakam, Jl. Sudirman No. 38 Petapahan, Lubuk Pakam 20512, Indonesia \\ ${ }^{1}$ anggisnani@gmail.com*; ${ }^{2}$ fadlilahw.7@gmail.com; ${ }^{3}$ irmayani_ph06@gmail.com; ${ }^{4}$ rosita.ginting38@gmail.com; ${ }^{5}$ raisha.oct@gmail.com; \\ *correspondence author
}

\section{ARTICLE INFO}

Article history

26-08-2021

17-09-2021

04-10-2021

Keywords

Low Back Pain

Worker

Bricks Maker

Age

Years of service

\begin{abstract}
Low back pain is one of the musculoskeletal disorders caused by repetitive movements and poor body activities. Almost $80 \%$ of the population has experienced low back pain in their life cycle. Low back pain is one of the most common complaints related to a job. The purpose of this study was to analyze the factors associated with the incidence of low back pain in brick-making workers. This research method is a quantitative research using a cross sectional design. The population is 38 people with purposive sampling technique sampling. Bivariate analysis using Chi Square test. The results showed that from 38 workers there were 25 people who experienced low back pain. The results of the chi square test showed that there was a relationship between age and low back pain $(p=0.001)$ and there was a relationship between years of service and low back pain $(\mathrm{p}=0.0001)$. It is recommended that workers always apply ergonomics principles in doing their work so as to reduce the level of risk of low back pain, for brick industry owners it is recommended to re-design work facilities and add mechanical aids to eliminate manual hazards, as well as suggestions for related agencies should make policies and supervision of problems in the informal sector, especially the brick industry.
\end{abstract}

\section{Pendahuluan}

Setiap pekerjaan memiliki risiko terhadap keselamatan dan kesehatan kerja. Besar kecilnya risiko tersebut tergantung pada jenis pekerjaan itu sendiri. Ada dua hal yang menjadi perhatian utama dalam keselamatan dan kesehatan kerja. Keselamatan kerja berhubungan dengan kecelakaan akibat kerja (KAK), sedangkan kesehatan kerja berhubungan dengan penyakit akibat kerja (PAK). Penyakit akibat kerja merupakan hal yang menjadi perhatian di dalam dunia ketenagakerjaan. Hal ini dikarenakan penyakit akibat kerja sangat berpengaruh terhadap efektivitas dan efisiensi pekerjaan dari seorang pekerja yang pada akhirnya akan menyebabkan penurunan produktivitas kerjanya [1]. Musculoskeletal Disorders (MSDs) merupakan salah satu penyakit akibat kerja. Keluhan pada sistem musculoskeletal adalah keluhan pada bagian-bagian otot rangka yang dirasakan oleh seseorang mulai dari keluhan sangat ringan sampai sangat sakit. Apabila otot menerima beban statis secara berulang dan dalam waktu yang lama, akan dapat menyebabkan keluhan berupa kerusakan pada sendi, ligamen dan tendon. Keluhan hingga kerusakan inilah yang biasanya disebut dengan MSDs [2]. Prevalensi penyakit muskuloskeletal di Indonesia yang pernah di diagnosis oleh tenaga kesehatan yaitu $11,9 \%$ dan berdasarkan diagnosis atau gejala yaitu $24,7 \%$. Jumlah penderita nyeri punggung bawah di Indonesia tidak diketahui pasti, namun diperkirakan antara $7,6 \%$ sampai $37 \%$.

Low back pain merupakan salah satu gangguan muskuloskeletal yang disebabkan oleh gerakan repetitif dan aktivitas tubuh yang kurang baik. Hampir $80 \%$ penduduk pernah mengalami low back pain dalam siklus kehidupannya. Low back pain atau nyeri punggung bawah menjadi salah satu keluhan yang sering dijumpai terkait dengan suatu pekerjaan [3]. Nyeri yang dirasakan pada bagian punggung bawah berasal dari tulang belakang daerah spinal, otot, saraf atau struktur lainnya yang terdapat pada daerah tersebut. Masalah tersebut dapat disebabkan akibat dari sikap 
tubuh yang tidak ergonomis sehingga membuat ketegangan pada otot-otot punggung bawah dan dapat menimbulkan kerusakan jaringan sekitar [4].

Menurut Health Safety Executive (HSE) dalam Work Related Musculoskeletal Disorders (WRMSDs) statistik di Inggris tahun 2017 menyebutkan pada tahun 2016 terdapat 507.000 pekerja yang menderita gangguan musculoskeletal terkait pekerjaan (berdiri sebentar atau berdiri lama). Akibatnya 8.9 juta hari kerja hilang terkait gangguan musculoskeletal. HSE juga mengelompokkan pekerja yang menderita Musculoskeletal Disorders (MSDs) berdasarkan efek pada area tubuh yang terkena. HSE menyebut ada lima industri dengan tingkat gangguan musculoskeletal yang lebih tinggi dari rata-rata per 100.000 pekerja dalam setahun, yaitu industri kontruksi ada 2300 kasus, industri pertanian kehutanan dan perikanan terdapat 2000 kasus, industri transportasi dan penyimpanan terdapat 1700 kasus, industri kesehatan dan pekerja sosial terdapat 1.600 kasus, dan industri lainnya terdapat 1200 kasus.

Hasil penelitian Octaviani (2017) yang dilakukan pada sopir bus antar provinsi di Bandar Lampung ditemukan 73,3 \% sopir bus antar provinsi mengalami MSDs pada bagian punggung bawah, betis, bahu, lutut dan leher. Dari keseluruhan sopir yang mengalami MSDs 66,2 \% menderita MSDs tingkat sedang [5]. Low Back Pain (LBP) adalah masalah yang banyak dihadapi oleh banyak negara dan menimbulkan banyak kerugian. Dilihat dari data yang dikumpulkan dari penelitian Pusat Riset dan Pengembangan Pusat Ekologi Kesehatan, Departemen Kesehatan yang melibatkan 800 orang dari 8 sektor informal di Indonesia menunjukkan keluhan LBP dialami oleh $31,6 \%$ petani kelapa sawit di Riau, 21\% pengrajin wayang kulit di Yogyakarta, 18\% pengrajin onix di Jawa Barat, $16 \%$ penambang emas di Kalimantan Barat, 14,9\% pengerajin sepatu di Bogor dan 8\% pengrajin kuningan di Jawa Tengah. Selain itu, pengerajin batu bata di Lampung dan nelayan di DKI Jakarta yang menderita keluhan LBP masing-masing 76,7\% dan 41\% [6].

Jenis pekerjaan lain yang berisiko terhadap terjadinya low back pain adalah pada produksi batu bata. Pekerjaan produksi batu bata terdapat posisi yang tidak ergonomis seperti postur tubuh yang janggal, beban kerja yang berat, pekerjaan berulang, ketidaktahuan pekerja tentang cara mengangkat beban yang sesuai dengan prinsip ergonomis saat melakukan pekerjaan. Hal ini terjadi pada tiga bagian proses pembuatan batu bata sampai bisa dijual pada konsumen. Proses tersebut yaitu pengolahan material tanah, proses pencetakan dan pengeringan, serta proses pembakaran. Ketiga proses ini memerlukan aktifitas fisik yang berat [7].

Aktifitas yang dilakukan pekerja di industri batu bata di Desa Sidourip berisiko mengalami low back pain. Hal ini dikarenakan pada proses pembuatan batu bata terdapat gerakan repetitif atau yang dilakukan secara berulang-ulang, pekerjaan pemindahan batu bata dilakukan secara manual, posisi membungkuk, beban yang diangkat tidak sesuai dengan batas beban maksimal dan pekerjaan dilakukan dalam waktu yang lama dengan posisi kerja yang tidak ergonomis. Fasilitas kerja yang kurang mendukung juga dapat membuat ketegangan otot atau gangguan pada struktur tubuh para pekerja, tata letak fasilitas produksi batu bata ini juga kurang seimbang dimana sering terjadi penumpukan bahan material yang akan digunakan dan juga luas kerja yang tidak standar sehingga mengganggu keleluasaan gerak dan kenyamanan pekerja. Berdasarkan temuan tersebut dan literatur yang telah ada, maka peneliti berasumsi penting dilakukan penelitian mengenai faktorfaktor yang berhubungan dengan kejadian low back pain.

\section{Metode}

Penelitian ini merupakan penelitian kuantitatif analitik observasional dengan menggunakan desain cross sectional. Populasi dalam penelitian ini adalah seluruh pekerja pembuatan batu bata bagian pengeringan di Desa Sidourip Kecamatan Beringin Kabupaten Deli Serdang sejumlah 56 orang. Sampel dalam penelitian ini adalah bagian dari jumlah dan karakteristik populasi, teknik yang digunakan dalam penelitian ini adalah purposive sampling. Jumlah sampel ditentukan berdasarkan pertimbangan beberapa kriteria inklusi dengan menggunakan rumus Lemeshow [8], sehingga diperoleh hasil perhitungan sampel sebesar 38 orang.

Data primer diperoleh dari hasil wawancara dengan menggunakan kuesioner terstruktur untuk mendapatkan data demografi subjek penelitian antara lain umur, pendidikan terakhir dan masa kerja. Data penyakit akibat kerja yaitu kejadian low back pain diperoleh dari hasil 
wawancara dengan berpedoman pada lembar observasi. Data sekunder diperoleh dari Kantor Kepala Desa Sidourip Kecamatan Beringin Kabupaten Deli Serdang. Variabel dalam penelitian ini terdiri dari variabel independen dan independen. Variabel independen yaitu umur, pendidikan terakhir dan masa kerja, sedangkan variabel dependen adalah kejadian low back pain. Pengolahan dan analisis data yang dilakukan secara deskriptif yaitu analisis univariat untuk menjelaskan secara distribusi frekuensi variabel penelitian dan analisis bivariat menggunakan uji chi square, apabila memenuhi syarat digunakan Pearson chi square dan apabila tidak memenuhi syarat digunakan Fisher's Exact.

\section{Hasil dan Diskusi}

Penelitian ini dilakukan pada pekerja pembuat batu bata di Desa Sidourip Kecamatan Beringin Kabupaten Deli Serdang, dimana 55\% masyarakat di Desa tersebut bekerja sebagai pembuat batu bata. Berdasarkan hasil penelitian yang telah dilakukan, pekerja melakukan pekerjaan dengn posisi kerja yang tidak alamiah atau tidak ergonomis seperti posisi badan membungkuk, posisi mengangkat benda yang salah dan melebihi berat beban yang seharusnya, serta posisi jongkok dalam durasi yang cukup lama. Posisi kerja yang tidak ergonomis tersebut dapat mengakibatkan pekerja mengalami keluhan nyeri punggung bawah atau low back pain.
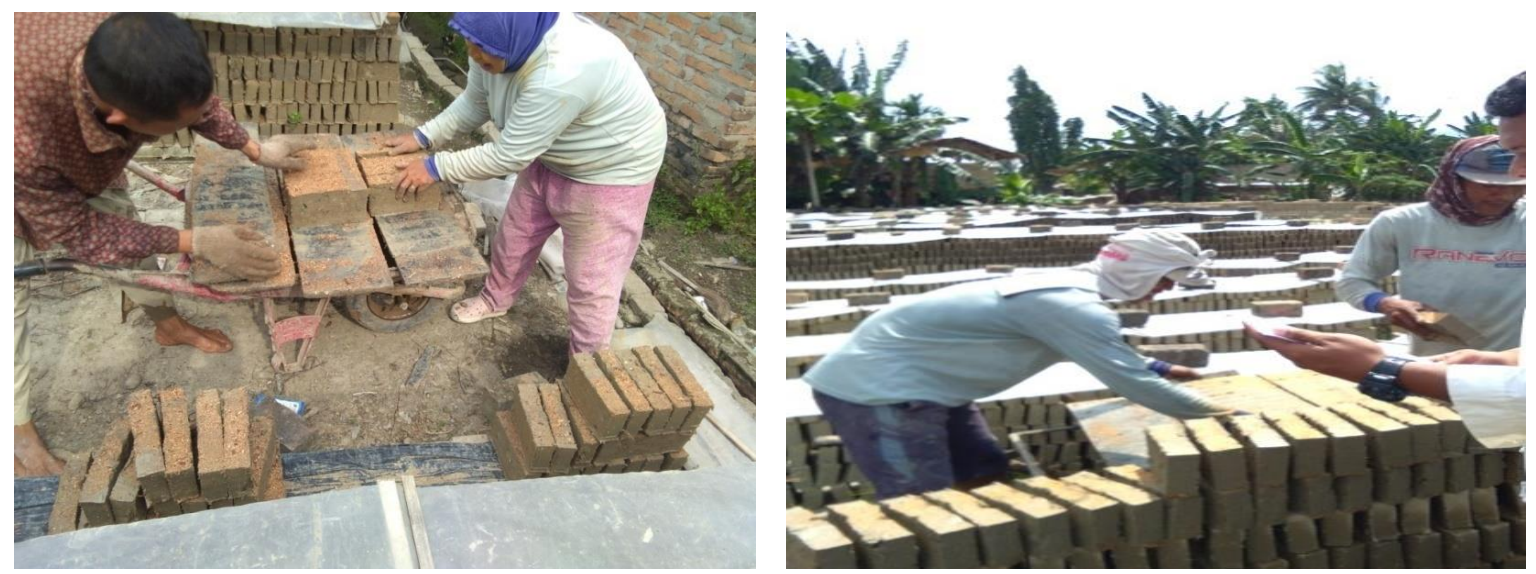

Gambar 1. Posisi pekerja saat melakukan pekerjaan

Berikut penyajian data berdasarkan hasil wawancara dan observasi yang telah dilakukan oleh peneliti.

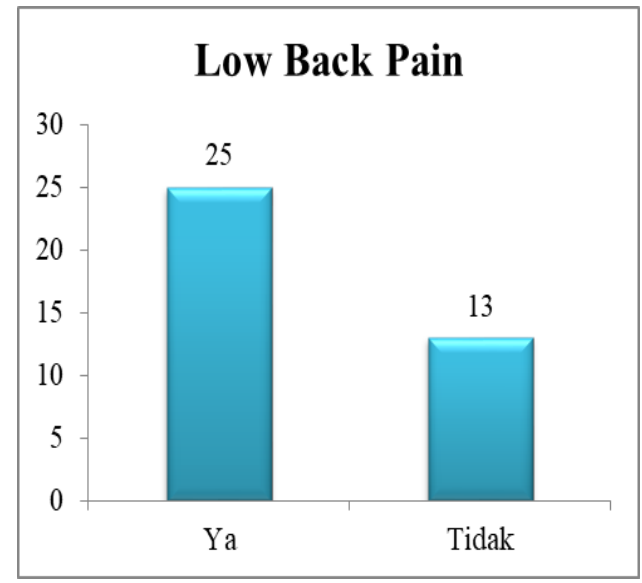

Gambar 2. Distribusi Frekuensi Kejadian Low Back Pain 
Berdasarkan Gambar 2 di atas diketahui bahwa pekerja pembuat batu bata yang mengalami low back pain sejumlah 25 orang $(65,8 \%)$ dan yang tidak mengalami keluhan low back pain sebanyak 13 orang (34,2\%). Low Back Pain (LBP) merupakan gangguan musculoskeletal yang bisa diakibatkan oleh aktivitas tubuh yang kurang baik. LBP dapat disebabkan oleh berbagai penyakit musculoskeletal, gangguan psikologis dan mobilisasi yang tidak benar. LBP merupakan rasa nyeri yang terjadi di daerah punggung bagian bawah dan dapat menjalar ke kaki terutama bagian belakang dan samping luar.

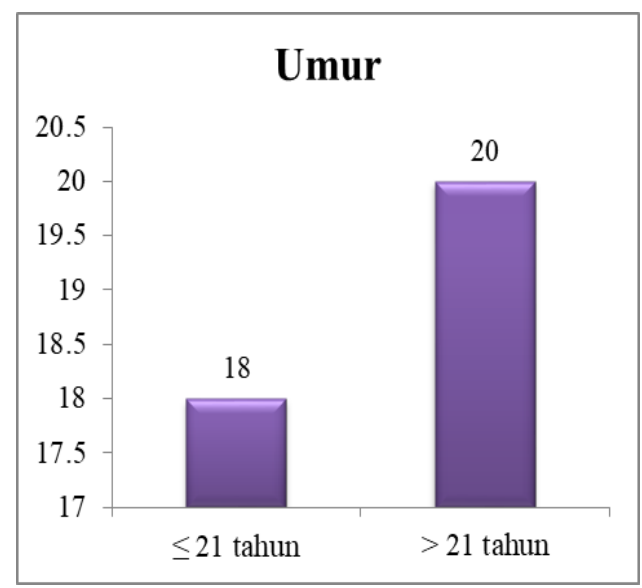

Gambar 3. Distribusi Frekuensi Umur Responden

Gambar 3 di atas menunjukkan bahwa mayoritas umur pekerja > 21 tahun sebanyak 20 orang $(52,6 \%)$ dan selebihnya yaitu 18 orang $(47,4 \%)$ umur pekerja $\leq 21$ tahun. Berdasarkan hasil uji chi square diperoleh hasil analisis untuk umur dengan angka significancy sebesar 0,001 $(\mathrm{p}<0,05)$, hal ini menunjukkan bahwa terdapat hubungan yang signifikan antara umur dengan kejadian low back pain.

Meningkatnya usia akan menyebabkan degenerasi pada tulang dan keadaan seperti ini akan terjadi ketika seseorang berusia 30 tahun. Pada usia 30 tahun terjadi degenerasi yang berupa kerusakan jaringan, penggantian jaringan menjadi jaringan parut, dan pengurangan cairan. Hal tersebut menyebabkan stabilitas pada tulang dan otot menjadi berkurang. Semakin tua seseorang, semakin tinggi risiko orang tersebut mengalami penurunan elastisitas pada tulang yang menjadi pemicu timbulnya gejala LBP.

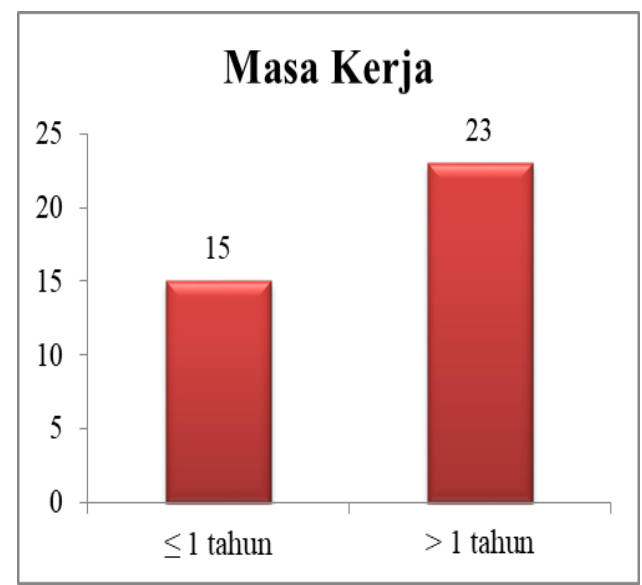

Gambar 4. Distribusi Frekuensi Masa Kerja Responden 
Gambar 4 di atas menunjukkan bahwa mayoritas pekerja dengan masa kerja $>1$ tahun sebanyak 23 orang $(60,5 \%)$ sedangkan pekerja dengan masa kerja $\leq 1$ tahun sebanyak 15 orang $(39,5 \%)$. Berdasarkan hasil uji chi square diperoleh hasil analisis untuk masa kerja dengan angka significancy sebesar $0,0001(\mathrm{p}<0,05)$, hal ini menunjukkan bahwa terdapat hubungan yang signifikan antara masa kerja dengan kejadian low back pain.

Hasil penelitian ini sejalan dengan penelitian yang telah dilakukan oleh Putri dkk pada tahun 2012, ditemukan hubungan antara masa kerja dengan kejadian low back pain pada pekerja pembersih kulit bawang dengan nilai $p$ value sebesar $0,001(<0,05)$. Demikian dengan penelitian yang dilakukan oleh Sangadji mengenai hubungan antara masa kerja dan durasi mengemudi dengan keluhan LBP di pangkalan CV. Totabuan Indah Manado, dimana dalam penelitiannya mengatakan bahwa ada hubungan antara masa kerja dengan kejadian LBP dengan nilai $\mathrm{p}<0,05$ [9].

Masa kerja merupakan salah satu faktor yang dapat menjadi faktor pemicu munculnya muscoskeletal disorder yang disebabkan oleh pekerjaan. Pekerja dengan peningkatan masa kerja akan melakukan gerakan yang sama dan berulang. Sehingga dapat memicu terjadinya kelelahan jaringan, dalam hal ini jaringan otot yang dapat menyebabkan overuse, sehingga bisa menimbulkan spasme otot. Munculnya kondisi ini sebagai efek fisiologis dari otot untuk mempertahankan atau mencegah kerusakan yang lebih lanjut dari suatu jaringan, spasme otot ini adalah respons dari tubuh untuk memberikan informasi ke diri kita untuk menyudahi aktifitas yang dilakukan dan segera beristirahat agar tubuh dapat tetap terjaga dengan baik. Selain itu masa kerja yang lama akan mengakibatkan rongga diskus menyempit secara permanen dan akan mengakibatkan degenerasi tulang belakang yang akan menyebabkan LBP [10].

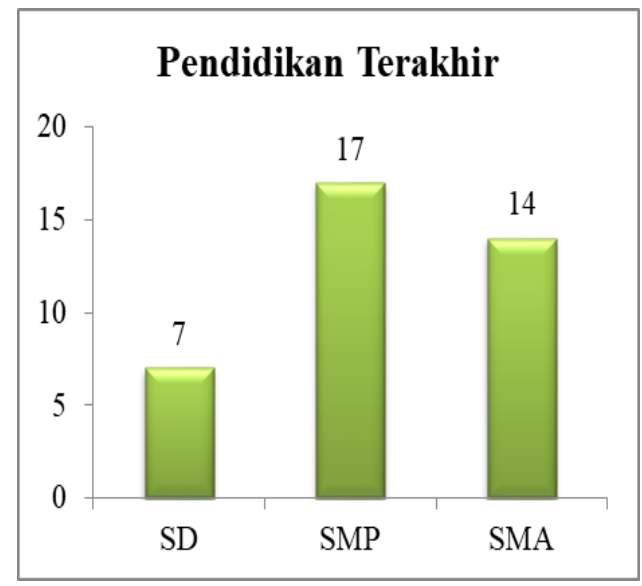

Gambar 5. Distribusi Frekuensi Pendidikan Terakhir Responden

Gambar 5 menunjukkan bahwa mayoritas pendidikan terakhir pekerja adalah SMP sebanyak 17 orang $(44,7 \%)$, sedangkan SMA sebanyak 14 orang $(36,9 \%)$ dan SD sebanyak 7 orang $(18,4 \%)$. Berdasarkan hasil uji chi square diperoleh hasil analisis untuk pendidikan terakhir dengan angka significancy sebesar 0,126 ( $>00,05)$, hal ini menunjukkan bahwa tidak terdapat hubungan yang signifikan antara pendidikan terakhir dengan kejadian low back pain. 


\section{Kesimpulan}

1. Pekerja pembuat batu bata yang mengalami keluhan low back pain sebanyak 25 orang, dari 38 orang yang diteliti.

2. Terdapat hubungan yang bermakna antara umur dengan kejadian low back pain dengan nilai $p$ sebesar $0,001(\mathrm{p}<0,05)$.

3. Terdapat hubungan yang bermakna antara masa kerja dengan kejadian low back pain dengan nilai $p$ sebesar $0,0001(\mathrm{p}<0,05)$.

\section{Saran}

1. Pemilik tempat kerja perlu melakukan re-desain fasilitas kerja agar tercipta tempat kerja yang aman dan nyaman serta menambah alat bantu mekanik untuk menghilangkan bahaya manual.

2. Pekerja dihimbau agar selalu menerapkan prinsip ergonomi dalam bekerja sehingga dapat menurunkan tingkat risiko terjadinya low back pain.

3. Dinas terkait agar dapat memberikan edukasi kepada pemilik industri batu bata dan kepada pekerja terkait dengan keselamatan dan kesehatan kerja di sektor informal, khususnya tentang low back pain dan cara pencegahannya.

\section{Referensi}

[1] Ariani, Farida, "Analisis Postur Kerja dalam Sistem Manusia Mesin untuk Mengurangi Fatigue Akibat Kerja pada Bagian Air Traffic Control (ATC) di PT. Angkasa Pura II Polonia Medan”. Jurnal Dinamis Vol. II, No. 6. Medan: Fakultas Teknik Universitas Sumatera Utara. 2018.

[2] Tarwaka, dkk. Ergonomi untuk Keselamatan, Kesehatan Kerja dan Produktivitas. Surakarta: UNIBA Press. 2004.

[3] Kusumaningrum, D. Hubungan Sikap dan Lama Duduk dengan Keluhan Nyeri Punggung Bawah pada Mahasiswa Fakultas Kedokteran X. Jakarta: Universitas Trisakti. 2019.

[4] Suma'mur. Higiene Perusahaan dan Kesehatan Kerja (Hiperkes). Edisi Kedua. Cetakan Pertama. Jakarta: Sagung Seto. 2014.

[5] Octaviani., Hubungan Postur Kerja Dan Faktor Lain Terhadap Keluhan Musculoskeletal Disorder's (MSDs) Pada Sopir Bus Antar Provinsi Di Bandar Lampung. (Jurnal Elektronik), Diakses di http://digilib.unila.ac.id/25390/. 2017.

[6] Sakinah, Djajakusli R., \& Naeim F. "Faktor yang Berhubungan dengan Keluhan Nyeri Punggung Bawah pada Pekerja Batu Bata di Kelurahan Lawawoi Kabupaten Sidrap". Jurnal, 1-10. 2012.

[7] Ismawati, Titi. "Analisis Postur Kerja dan Re-Desain Fasilitas Kerja Pada Pengrajin Batu Bata Di Kelurahan Kalase'rena Kec. Bontonompo Kab. Gowa”. Skripsi. Makassar: Fakultas Kedokteran Universitas Hasanuddin. 2017.

[8] Lemeshow, S., David, W., Janelle, K., and Stephen, K., 1997. Besar Sampel dalam Penelitian Kesehatan (Terjemahan Dibyo Pramono), Yogyakarta: Gadjah Mada University Press.

[9] Sangadji, S.A.A. Hubungan antara Masa Kerja dan Durasi Mengemudi dengan Keluhan Nyeri Punggung Bawah di Pangkalan CV. Totabuan Indah Manado. Fakultas Kesehatan Masyarakat Universitas Sam Ratulangi. 2014.

[10] Pratiwi. Beberapa Faktor yang Berpengaruh Terhadap Keluhan Nyeri Punggung Bawah Pada Penjual Jamu Gendong. Jurnal Promosi Kesehatan Indonesia Vol. 4 (1). Pp 63-64. 2009. 